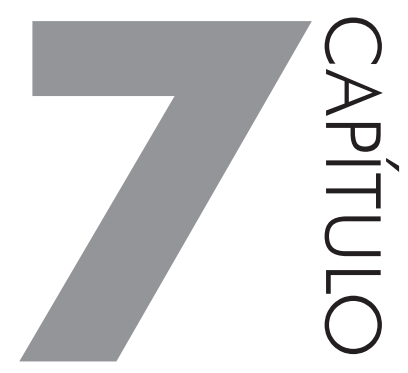

\title{
PROJETO ENGAGE NO ENSINO SUPERIOR: UMA EXPERIÊNCIA DE PESQUISA E INOVAÇÃO RESPONSÁVEIS NA DISCIPLINA DE LIBRAS
}

\section{PATRICIA LUPION TORRES, NEIDE MITIYO SHIMAZAKI, RAQUEL PASTERNAK GLITZ KOWALSKI}

\section{INTRODUÇÃO}

A discussão no Ensino Superior centra-se na necessidade de mudança epistemológica quando considera-se o movimento mundial de conceber a educação como um direito de todos.

Os diferentes graus no Ensino Superior tentam viabilizar os princípios da inclusão escolar nos currículos dentro das infraestruturas existentes, no entanto, para Denari (2008, p. 42), "a visão tradicional do conhecimento, da relação entre sujeito-objeto e a aprendizagem, seja (re)considerada, (re)significada" em virtude da determinação de educar "na" e "para" diversidade.

Sob esta ótica, as políticas públicas determinam a frequência de todos as pessoas na escola, independentes das condições étnicas, de classe, de gênero, enfim, seguem os princípios da educação inclusiva proclamadas na Declaração de Salamanca, em 1994 e o Brasil foi o signatário. (Brasil, 1994)

As políticas educacionais inclusivas requerem o cumprimento do direito à educação, com respaldo “(...) no conceito de um processo pedagógico significativo, justo, participativo e engajado culturalmente (...)" (Dorziat, 2008, p. 32). Corrobora-se, assim, que a inclusão escolar legítima "não pode atropelar e limi- 
tar pontenciais, dificultar acesso ao conhecimento e à cidadania, ao contrário deve ser via de desenvolvimento humanos" (Idem, p. 34), principalmente aos alunos com deficiências.

Pelo Decreto n. 7.211/2011, no artigo $1^{\circ}$, define como público-alvo da educação especial e do processo de inclusão escolar "as pessoas com deficiência, com transtornos globais do desenvolvimento e com altas habilidades ou superdotação" e no parágrafo $2^{\circ}$ especifica que "no caso dos estudantes surdos e com deficiência auditiva serão observadas as diretrizes e princípios dispostos no Decreto n. 5.626, de 22 de dezembro de 2005". (Brasil, 2011, s/p)

As pessoas surdas têm o direito linguístico assegurado pelo Decreto n. 5.626/2005 e as escolas precisam pensar em um ambiente linguísticos, pedagógicos e culturalmente propícios para um ensino e aprendizado apropriados.

Para que a inclusão de alunos surdos ocorra requer profissionais que conheçam as especificidades comunicativas dos surdos e que tem a Língua Brasileira de Sinais - Libras - como a língua oficial, que significa que é a primeira língua (L1) dos surdos e a segunda a Língua Portuguesa escrita (Brasil, 2005). Assim, o Decreto n. 5.626 de 2005, no capítulo II, que diz respeito à inclusão de Libras como disciplina curricular, atribui a obrigatoriedade.

Nos cursos de formação de professores para o exercício do magistério, em nível médio e superior, e nos cursos de Fonoaudiologia, de instituições de ensino, públicas e privadas, do sistema federal de ensino e dos sistemas de ensino dos Estados, do Distrito Federal e dos Municípios. (Brasil, 2005, art. $3^{\circ}$, s/p)

A obrigatoriedade citada gera um panorama inédito no Ensino Superior que associa aos objetivos de viabilizar uma formação profissional que assegure a compreensão de que as pessoas surdas têm a igualdade de condição de acesso às informações, tanto acadêmicas como de convívio social, tal como um ouvinte.

Em termos de tempo histórico, as experiências do ensino e aprendizagem de Libras para alunos do Ensino Superior ainda são incipientes, conforme observa Shimazaki (2017). Também, verifica que há uma carência de pesquisa, referenciais, sobretudo há falta de materiais didáticos em Libras para os alunos do Ensino Superior.

Os prospectos dos estudiosos das tecnologias educacionais, tais como Torres (2004), Okada (2008), Santana (2012), Tsukamoto e Fialho (2014), entre outros, inserem a educação no contexto da sociedade da informação e comunicação e sugerem formas de ensinar e aprender criativamente, sem barreiras de expandir o conhecimento, empreendendo um processo colaborativo e responsável entre os sujeitos envolvidos. Para tal, advogam os Recursos Educacionais Abertos - REA.

O movimento de REA teve amparo da Organização das Nações Unidas para a Educação, a Ciência e a Cultura (Unesco) que conceituou em 2012, com fins de 
disponibilizar o conhecimento formatado em materiais de ensino e aprendizagem sob licenças abertas - os Criative Commons - e nas diferentes formas de reutilização, recriação, remixagem e redistribuição, amparado em qualquer mídia digitais (REA, <http://rea.net.br/site>)

Considera-se que as tecnologias abertas e as metodologias abertas constituem elementos fundamentais para a construção e compartilhamento transparente dos REA, que ancoram-se no uso extensivo dos recursos da Web.2 ${ }^{1}$. (Shimazaki, 2017, p. 21)

Vale destacar que este estudo se vinculou a Responsible research and innovation (Pesquisa e Inovação Responsáveis - RRI), proposto pela União Europeia, que associa-se ao Projeto Engage, que coloca em pauta as discussões de temas que tragam benefícios ao futuro da humanidade, na premissa de promover a inclusão digital das pessoas e nas práticas escolares para facilitar o acesso aos conhecimentos científicos elaborados e disponibilizados nos formatos de Recursos Educacionais Abertos (REA).

O currículo desenvolvido pela ENGAGE envolvendo RRI fornece uma estrutura que integra quatro áreas do conhecimento da ciência e da sociedade: impacto tecnológico, grande ciência, pensamento de valores e meios científicos. Além disso, este currículo é baseado em dez habilidades de pesquisa científica para RRI, a fim de proporcionar aos alunos o envolvimento ativo na ciência contemporânea. (Torres, Fialho, Kowalski \& Okada, 2016, p. 2143)

Assim, o grupo de pesquisa vinculada à universidade representante do Projeto Engage no Brasil e ressalta-se que este estudo analisa o processo de ensino e aprendizado da Libras no Ensino Superior com o objetivo que os alunos ouvintes apreendam a Libras em contextos interativos, que confluem com os objetivos do Projeto Engage de discutir o tema, no caso os transgênicos, a fim de gerar ensino e aprendizagem colaborativa e divulgar no formato de REA.

Destaca-se que os princípios da aprendizagem colaborativa destacada por Torres e Irala (2007), que apontam a participação dos alunos no processo de produção de conhecimento neste processo.

A interatividade, a incorporação do conceito de diversidade e inclusão no aprimoramento da visão da sociedade com múltiplas culturas e, sobretudo a ca-

1 Web 2.0 significa a segunda geração de comunidades e serviços oferecidos na rede de comunicação, baseados em redes sociais e tecnologias de informação, que permite a interação e participação com o acréscimo de linguagens mediante ao uso de aplicativos cada vez mais veloz e dinâmico com os usuários colaborando e organizando as informações. Disponível em: <http://brasilescola.uol.com.br/informatica/web-20.htm>. Acesso em: 13 out. 2017. 
pacidade criativa dos participantes, que elaboraram um vídeo em Libras sobre os alimentos transgênicos, devem ser considerados processo de inovação para o legado educacional.

\section{LIBRAS NO ENSINO SUPERIOR}

O Ensino Superior está envolto na busca de alternativa para minimizar a distância entre a formação profissional que se propõe com o enfrentamento dos desafios do cotidiano da sociedade e na proposta de formar profissionais com visão de inclusão escolar e social coloca-se como mais uma afronta entre outras causas menos receptoras.

A proposta de uma educação inclusiva impõe às Instituições do Ensino Superior (IES), a execução das políticas públicas e serviços, na qual Denari (2008, p. 37) observa que "vem obrigando os agentes responsáveis, nos âmbitos legal e acadêmica, a realizar ajustes curriculares de acordo com diferentes enfoques" e complementa que "a inclusão constitui um desafio dificilmente concretizado, por envolver custos de diversas naturezas e problemas associados à gestão institucional e ao desempenho profissional".

A citação da obrigatoriedade da disciplina de Libras nos cursos de formação de professores, no Decreto n. 5.626/2005, também pontua na sequência do artigo $3^{\circ}$, que

$\mathbb{S} 1^{\circ}$ Todos os cursos de licenciatura, nas diferentes áreas do conhecimento, o curso normal de nível médio, o curso normal superior, o curso de Pedagogia e o curso de Educação Especial são considerados cursos de formação de professores e profissionais da educação para o exercício do magistério.

$\mathbb{S} 2^{\circ} \mathrm{A}$ Libras constituir-se-á em disciplina curricular optativa nos demais cursos de educação superior e na educação profissional, a partir de um ano da publicação deste Decreto.

Como disciplina curricular obrigatória e optativa nos demais cursos pressupõe que o Ensino Superior, destaca a necessidade de considerar as características da Libras, que representa uma língua visual, espacial e cinestésica que do professor em formação e dos futuros profissionais de diferentes cursos de graduação, exige essa compreensão, pois o aluno surdo incluso requer adaptações curriculares visuais, além, do apoio educacional especializado permanente, na figura do tradutor e intérprete em língua de sinais e Língua Portuguesa (TILS). (Brasil, 2005)

Outro ponto a ser considerado diz respeito à estrutura linguística da Libras. Comparada ao aprendizado de outras línguas estrangeiras, a Libras para os ouvintes, comentam Slomsky (2012), Lacerda (2014), Shimazaki (2017), entre outros pesquisadores, requer o uso de habilidades orais e auditivas. As habilidades 
como o uso da visão, associado à memória cinestésica e orientação espacial, além da linguagem corporal e facial, são exigidas no aprendizado da Libras, que representam uma língua complexa para os ouvintes.

Deve-se considerar a particularidade de cada aprendente e que o Ensino Superior é locus de formação profissional declarada nas políticas educacionais, sobretudo na Leis de Diretrizes e Bases (LDB) n. 9394 de 1996 (Brasil, 1996).

A legalidade atribui a responsabilidade do Ensino Superior em elaborar o conhecimento em interação com múltiplas realidades, dentre as quais, a especificidade comunicativa dos surdos. De modo que, "as relações humanas ocorrem na aceitação mútua, reconhecendo a legitimidade do outro" e que o professor "deixa de ser somente o transmissor de conhecimento para se transformar em um facilitador de condições que acarretam mudanças estruturais em seus alunos". (Denari, 2008, p. 42-43)

Evidencia-se as tendências e desafios no uso das tecnologias aplicadas ao Ensino Superior conforme a publicação americana Horizon Report 2013 citado por Rodrigues (2016), que sugere a avaliação, a pesquisa, formação de ensino e aprendizagem, nas quais, afirma que "as novas tecnologias com velhas pedagogias não funcionam” (Gomez s/d apud Rodrigues, 2016, p. 65).

As ações de renovar e inovar a educação em a conexão ao uso das tecnologias na educação, conforme Rodrigues (2016), deve promover a reflexão e buscar as metodologias ativas de ensino-aprendizagem, que valorize o conhecimento técnico e prático respaldado em pesquisas, interesse comunitário, debates temáticos, participação de projetos colaborativos, enfim, tem como o suporte das tecnologias propiciada pela Web.2 para uma inteligência coletiva e aprendizado colaborativo.

As tecnologias associadas às pesquisas educacionais também se compactuam com os projetos de Pesquisa e Inovação Responsáveis (RRI) apresentados nos próximos parágrafos.

\section{O PROJETO ENGAGE SOB A RESPONSABILIDADE PESQUISA E INOVAÇÃO (RESPONSIBLE RESEARCH AND INNOVATION - RRI) NO USO DE REA NO ENSINO SUPERIOR}

A qualificação profissional constitui o enfoque do Ensino Superior brasileiro e nas últimas décadas, as políticas públicas determinam a democratização de acesso.

Os programas como ProUni (Universidade para Todos), a Universidade Aberta do Brasil (UAB) e o Reuni (Programa de Reestruturação e Expansão das Universidades Federais) são, segundo Pereira e Silva (2010), os principais progra- 
mas no que tange à expansão do Ensino Superior, além do aumento da oferta do crédito educativo (FIES), que confluem com os níveis e modalidades educacionais que determinam as condições igualitárias de acesso e permanência.

Tais programas estatais refletem em transformações nas IES, que demandam mudanças de ações que exigem não somente a funcionalidade de uma universidade meramente operacional, que vai além da transmissão rápida de conhecimentos para assegurar o ingresso rápido no mercado de trabalho, com risco de formarem profissionais que tornam-se descartáveis e obsoletos com o tempo (Barreto, 2002).

Este panorama "complexo e diversificado", afirma André (2009, p. 75) refletem diretamente no cotidiano dos professores universitários, que são desafiados "a repensar os conhecimentos, as práticas, as atitudes e os valores que até então lhe serviam de base e buscam reestruturar seus saberes em respostas às novas pesquisas".

Entende-se, no contexto da IES contemporâneo, que a responsabilidade do Ensino Superior de formar recursos humanos adequados ao desenvolvimento econômico e social da sociedade, por meio de ensino, pesquisa e extensão, requer os acréscimos de abordagens educacionais com perspectivas inovadoras.

As abordagens educacionais solicitadas resultam das orientações fundamentadas em práticas educacionais inovadoras, que conforme Behrens (2011), respaldadas no paradigma da complexidade, na visão orientada para a busca de resultados socialmente significativos, inseparável da tecnologia que atrela-se às possibilidades de ensinar e aprender para "postar-se diante da profissão e entendê-la nas suas dimensões interacionais sociais, éticas e políticas”. (André, 2009, p. 79)

Nesta perspectiva, a União Europeia criou o European Group on Ethics in Sciences and New Technologies - EGE, ao final da década de 1990, comentam Torres, Okada e Kowalski (2016), em decorrência da necessidade de promoção tecnológica na educação. Neste segmento, as autoras apresentam a Comissão Europeia como o propulsor da ideia de Responsible Research and Innovation - RRI, que foi vinculada ao programa Horizon 2020, com a intenção de associar os impactos éticos e sociais na pesquisa e a sua meta avaliação.

A Pesquisa e Inovação Responsáveis é uma abordagem que antecipa e avalia as implicações potenciais e as expectativas da sociedade em matéria de investigação e inovação, com o objetivo de promover o desenho de uma investigação e inovação inclusivas e sustentáveis. (Comissão Europeia, 2012)

A abordagem da RRI destaca a transparência, inovação e interação de forma colaborativa entre os cidadãos do mundo, em discussões que se fundamentam em necessidades sociais, expectativas e valores éticos para melhor alinhar os resultados da inovação. (Okada, Young \& Sherborne, 2015) 
A proposta da RRI pressupõe um processo educacional diferenciado para a próxima geração, para Ratcliffe (2003) e Ryan (2015) citado por Torres, Okada e Kowalski (2016, p. 281) "de modo a garantir a alfabetização científica e a investigação responsável, visando o engajamento público nos processos da pesquisa e nas decisões para a inovação", assim, consolida-se em uma estrutura curricular condizente com a inclusiva escolar.

Os dispositivos tecnológicos podem ser utilizados, criadas no ensino colaborativo, que segundo Torres e Irala (2007, p. 70) pode-se ser caracterizada de múltiplas formas e apontam a interação de grupos que permite “(...) a troca de ideias com outras pessoas melhora o pensamento e aprofunda o entendimento" que vai além de somar mãos para execução de um trabalho.

O Projeto Engage formata as estratégias de potencializar a consciência em escala da RRI, por meio de Recursos Educacionais Abertos, que destacam as quatro áreas de conhecimento da ciência-sociedade, que são os impactos da tecnologia, ciência, valores do pensamento e ciência na mídia, que soma-se às dez habilidades de investigação científica para RRI, que são: "interrogar fontes, usar ética, examinar consequências, estimar riscos, analisar padrões, criticar reclamações, justificar opiniões, comunicar ideias, elaborar perguntas e tirar conclusões”. (Okada, Young \& Sherb, 2015 apud Torres, Okada \& Kowalski, 2016, p. 282)

No Brasil, uma universidade de grande porte de origem às discussões sobre RRI, em 2015, como parte das atividades do grupo de pesquisa do Programa de Pós-Graduação em Educação, foi desenvolvido pela rede de pesquisa COLEARN, que investiga REA, por meio da plataforma (engagingscience.eu), que segundo Okada, Young e Sherborne (2015), combina REA, cursos on-line abertos e comunidade de prática para o ensino inovador.

Em respeito a difusão de conhecimento e a diversidade humana, Litto (2013, p. 11) apud Shimazaki (2017), denomina "copyleft" (em oposição ao "copyri$g h t$ ") ou "recursos educacionais abertos" (REA ou, em inglês, OER), que mediante ao uso de licenças aberta "Criative Commons" que aumentam a propagação dos estudos e atribui ao Ensino Superior à função de acesso aos materiais de conteúdos intelectuais valiosos.

O REA foi conceituado como sendo materiais de uso didáticos amparados em qualquer suporte de mídia de domínio público ou sob licenças, permitindo que sejam reutilizados, aprimorado, redistribuídos e recombinados dos conteúdos de aprendizados organizados em cursos, materiais, tópicos, metodologias de ensino, dos utilizados ou adaptados por terceiros. (<http://rea.net.br/site>)

Os conteúdos de aprendizado, ferramentas técnicas e recursos para implementação representam os três elementos do REA, com o foco principal que qual- 
quer conteúdo postado em alguma mídia pode ser utilizada e recombinada com fins de aumentar e propagar o conhecimento de todos (Idem).

O Projeto Engage conjectua o uso de REA e com os princípios da RRI de promover a inclusão de cidadãos na era digital, visando levá-los a compreender e avaliar os riscos e benefícios de desenvolvimentos científicos relacionados com contextos locais e globais, tal como as questões dos alimentos transgênicos, na unidade de estudo da agrobiodiversidade.

\section{O PROJETO ENGAGE E OS ALIMENTOS TRANSGÊNICOS NA DISCIPLINA DE LIBRAS}

O estudo sobre o ensino de Libras no Ensino Superior enquadra-se como pesquisa participativa caracterizada por Haguette (2003), Thiollent (2007) e Greenwood e Levin (2010), nas propostas de pesquisa de atuação social validada como uma pesquisa científica e qualitativa.

Na pesquisa participante Haguette (2003) considera três componentes que a caracteriza: a investigação, a educação e a ação na premissa que “(...) uma ação reflexionada em um processo orgânico de mudança cujos protagonistas são os pesquisadores e a população interessada na mudança”. (p. 141-143)

Destaca-se que este estudo revela que o ensino de uma língua - Libras - deve considerar as dez habilidades postulados pela RRI, principalmente a respeito de constituir uma educação intencionalmente inclusiva. Assim, por meio do grupo de estudos do programa de Pós-Graduação de uma universidade de grande porte do Estado do Paraná, associou-se ao Projeto Engage, no grupo de discussões sobre a agrobiodiversidade e alimentos transgênicos.

Constitui-se de aproximadamente 350 alunos de 13 cursos de graduação ofertada pela instituição, que aceitaram os termos éticos com o consentimentos e cedências de imagens para abalizar a pesquisa científica.

Entre os procedimentos da pesquisa, iniciou-se com a apresentação sobre a participação do Projeto Engage, com a exposição dialogada dos objetivos do Projeto Engage, os órgãos responsáveis e o tema alimentos transgênicos como foco das discussões coletiva para fomentar ações para preservação do futuro da humanidade.

O tema transgênico vinculou-se ao conteúdo da disciplina de Libras que previa o ensino de sinais de alimentos para os participantes da pesquisa.com destaque no objetivo de sinalizar os vocabulários relativos à

AGROBIODIVERSIDADE e os produtos TRANSGÊNICOS, contextualizados, direcionados e reutilizados em contextos dialógicos pelos futuros docentes e profissionais, considerados como futuros elementos de acessibilidades às informações de pessoas surdas na Língua Brasileira de Sinais - LIBRAS, ao mesmo 
tempo, com a formação de opinião críticas e participando das inovações tecnológicas científicas conectados com outros estudantes dos países envolvidos (Shimazaki, 2017).

Cientes da participação de discussões de Transgênicos, os 350 participantes iniciaram com a busca de fontes de informações sobre os transgênicos e agrobiodiversidade nas aulas de Libras.

\section{OS PROCESSOS DE APRENDIZADO DOS SINAIS EM LIBRAS E A ELABORAÇÃO DO REA SOBRE TRANSGÊNICOS}

Em sala de aula, as disciplinas de Libras tiveram a duas aulas com duração de $1 \mathrm{~h} 30 \mathrm{~min}$, totalizando duas semanas de participação dois momentos.

O primeiro momento foi destinado às reflexões sobre os dados levantados sobre os transgênicos, para a elaboração de um texto informativo. Cada grupo, composta de três a seis componentes, expôs o texto elaborado. As discussões foram oralizados pelos alunos e os grupos sugeriram que houvessem a produção de um texto coletivo, no formato de $w i k i^{2}$, em que cada grupo acrescentaria as ideias centrais sobre os alimentos transgênicos. Houve a produção de textos informativos e de opiniões de 13 cursos de graduação, nas quais, ampararam a produção de REA sobre os transgênicos.

Com base nas orientações de Felipe (2005) o registro escrito em Libras pode ser feito em letra maiúscula para registrar o texto que deve ser sinalizado. Orienta que o alfabeto manual/digital pode ser utilizado quando não há sinais, nesse caso, o registro é feito com a utilização de letras maiúsculas separados por hífen, dessa maneira: T-R-A-N-S-G-Ê-N-I-C-O-S. Essas, constituem uma das formas de registro escrito que Felipe (2005) aponta, o que ela denomina de transposição interlingual escrita da Língua Portuguesa para Libras, com o empréstimo linguístico da Língua Portuguesa.

O segundo momento da aula de Libras, foi destinada para sinalizar os alimentos em Libras que apareceram no texto, com complemento de todas as categorias semânticas que formam frutas, verduras, cereais, vegetais, alimentos salgados e doces, entre outros.

Em todos os grupos soletrou-se a palavra T-R-A-N-S-G-E-E-N-I-C-O-S, com base em Felipe (2005) que descreve as configurações de mãos para o uso do alfabeto digital/manual em Libras.

2 Wiki constitui uma ferramenta de edição com possibilidade de produção de texto de forma coletiva e livre, essa característica permite qualquer pessoa, mesmo sem conhecimentos técnicos, contribuir para os conteúdos de uma página Web. 


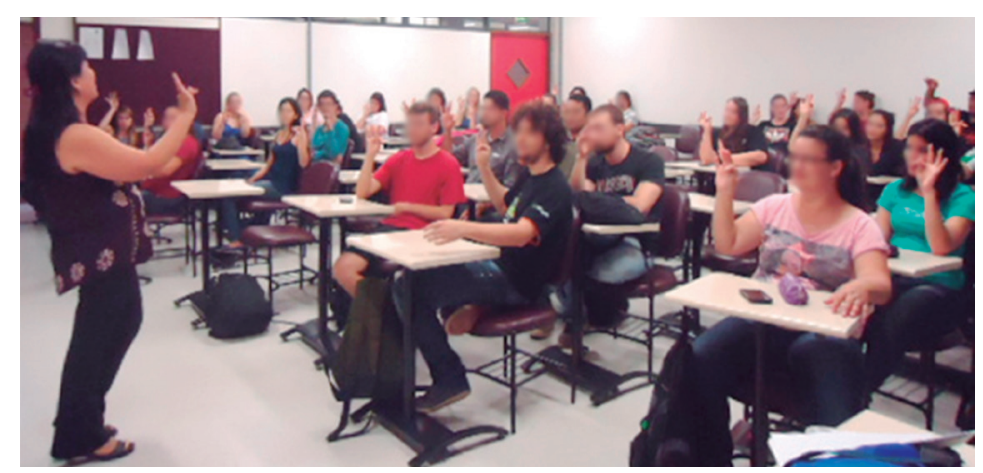

Figura 1 Soletração da palavra T-R-A-N-S-G-Ê-N-I-C-O-S em Libras.

Fonte: Acervo da pesquisadora com autorização de imagem captado em outubro 2015.

A conclusão dos alunos sobre os transgênicos foi de que nas pesquisas de sinais postados nos vídeos da Internet que o significado de TRANSGÊNICO não condiziam com verdadeiro significado, pois apresentavam conceitos em Libras como um sinal composto formado de duas palavras: feijão e mudar, que na orientação de Felipe (2005) o registro escrito em Libras seria FEIJÃO>MUDAR.

Os participantes argumentaram que não é só feijão que sofre modificações genéticas, pois, perceberam que nas leituras que a definição de transgênicos conferia como plantas geneticamente modificada no laboratório e que geram alimentos transgênicos. Como consequência, os alunos pesquisaram um sinal condizente com as definições pesquisadas.

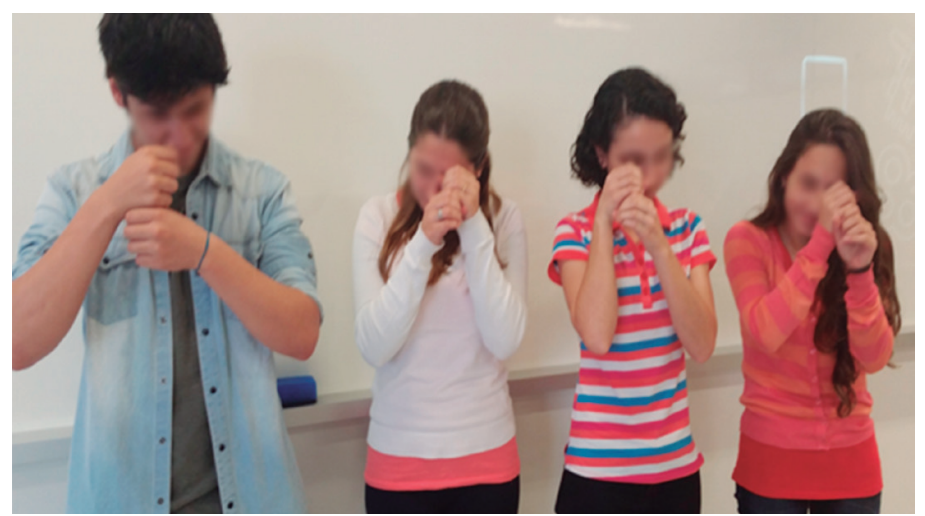

Figura 2 Sinal de Libras de laboratório.

Fonte: Acervo da autora captado em outubro 2015.

As observações críticas ocorreram também sobre as vídeo-aulas em Libras, que ensinavam a língua de sinais sem um contexto, nas metodologias de repetições e reproduções sem uma proposta de interação comunicativa. 
Outro ponto relevante da pesquisa dos alunos foi do conhecimento da existência do selo de transgênicos. Assim, os alunos escolheram um sinal específico para transgênicos, sugerido pelo grupo do curso de licenciatura em Química e os demais grupos participantes concordaram.

Vale destacar que o sinal inédito de transgênico criado e escolhidos pelos alunos necessita da aprovação da comunidade surda. Assim, a representante da comunidade surda, Adriana de Mello Guzzo, analisou e aprovou o sinal de transgênico (Figura 3) conferindo-o de uso nacional.

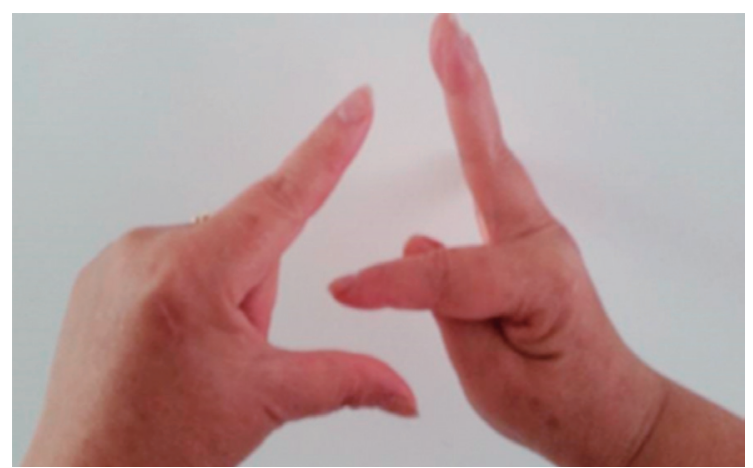

Figura 3 Sinal de alimentos transgênicos.

Fonte: Acervo da pesquisadora com cedência de imagens captadas em 2015.

Como atividade de consolidação de interação de linguagem os alunos participaram da exposição denominada "Agrobiodiversidade", resultado da produção de REA sobre a temática pelo curso de Design Gráfico e dentro das características do ensino colaborativo, os 350 participantes contemplaram a exposição de imagem expostos em cartazes fixos com questões sobre os transgênicos.

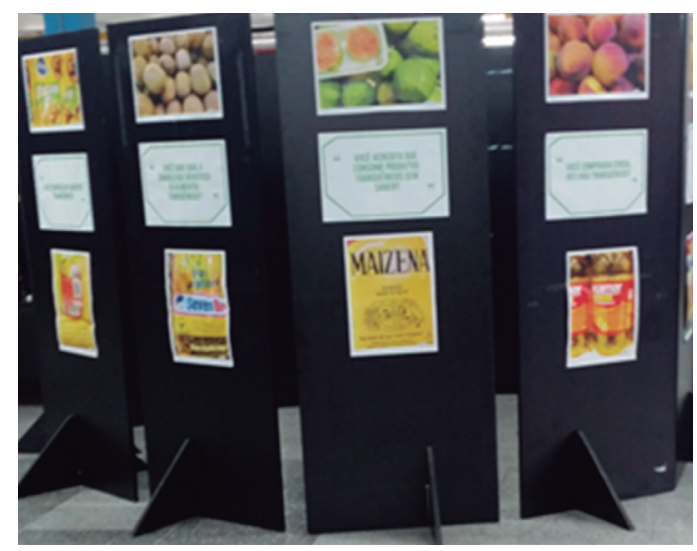

Figura 4 Exposição Agrobiodiversidade - alimentos transgênicos.

Fonte: Acervo da autora captado em outubro 2015. 
Mediante questões norteadoras, a exposição sobre Agrobiodiversidade - os alimentos transgênicos, possibilitaram aos alunos a participarem de formas variadas, com registro fotográficos e vídeo, feitos pelos alunos e pela pesquisadora, demonstrando o envolvimento com o projeto.

As questões foram sinalizadas e os alunos reuniram os saberes elaborados na sala de aula, de modo que o espaço destinado à exposição foi também de apresentações dos textos informativos e de opiniões sinalizados em Libras.

Os participantes utilizaram sinais em Libras em um contexto de interação e comunicação. As formas de participação foram variadas, tanto em duplas como individualmente.

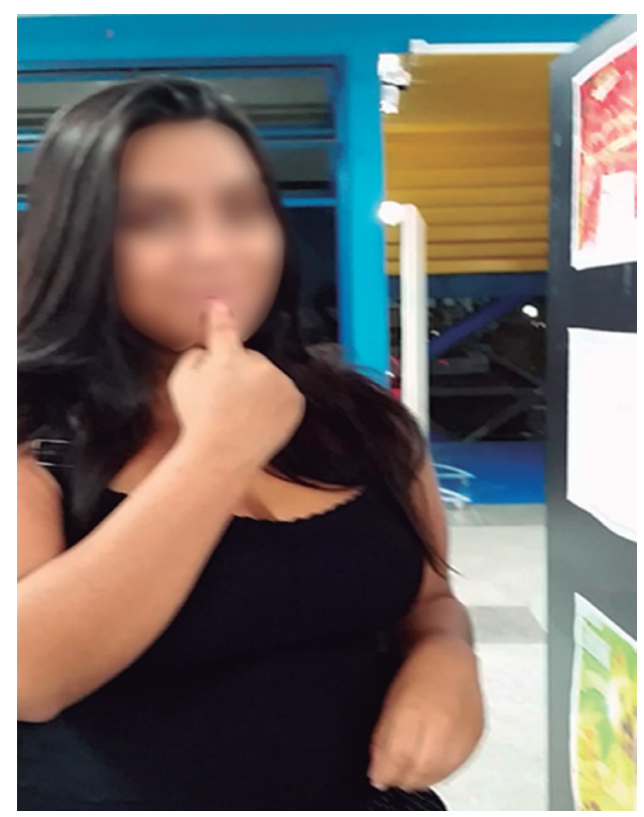

Figura 5 Sinal de vermelho para compor a palavra morango.

Fonte: Acervo da autora captado em outubro 2015.

Os alunos sinalizaram individualmente, também em duplas, de acordo com as figuras de alimentos expostas nos painéis da exposição.

Uma dupla de alunos do curso de licenciatura de Química apresentou em Libras, todas as questões sobre os transgênicos. Iniciaram com apresentação do objetivo da exposição.

A forma de apresentação condiz com Lacerda (2014) que afirma que a complexidade de aprender a Libras pode ser transposta quando exposta à sua estrutura de forma interativa. Derruba-se o conceito que requer habilidades extraordinárias para interagir em Libras. 


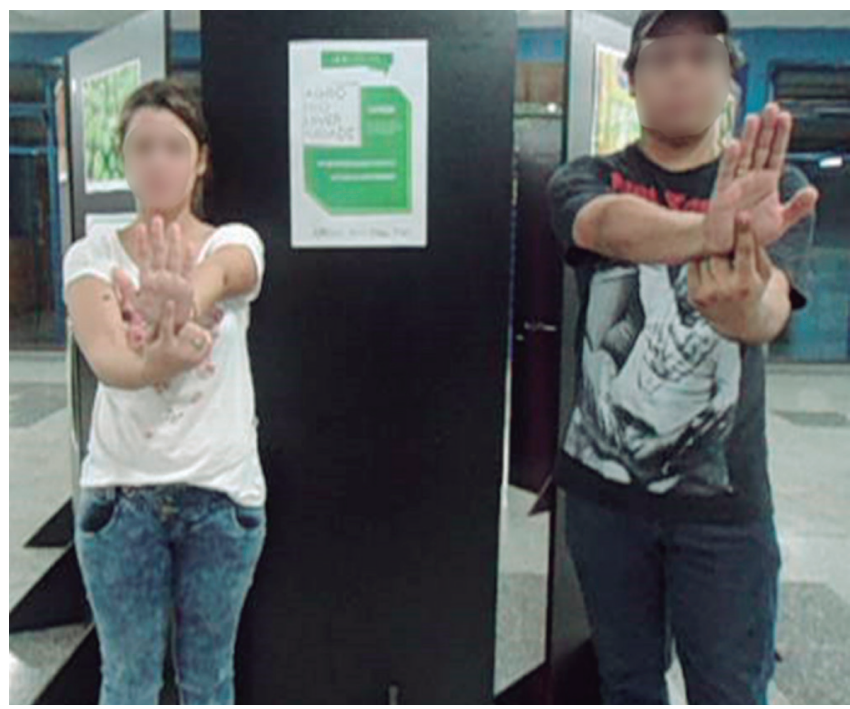

Figura 6 Sinal em Libras de exposição.

Fonte: Acervo da pesquisadora com cedência de imagens captadas em outubro 2015.

A maioria dos 350 alunos participaram coletivamente da exposição. O grupo de alunos do curso de Ciências Sociais apresentaram o texto coletivo elaborado em sala de aula, no formato de wiki.

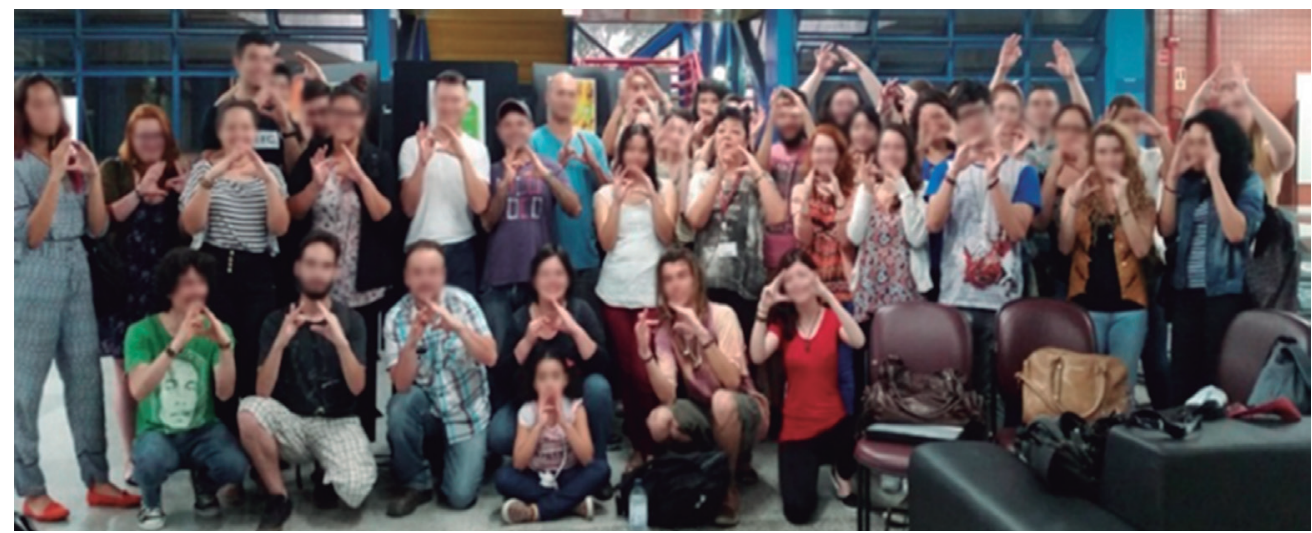

Figura 7 Grupos de alunos do curso de Ciências Sociais.

Fonte: Acervo da pesquisadora com cedência de imagens captadas em outubro 2015.

As atividades em salas de aulas e a participação da exposição de agrobiodiversidade foram registradas em fotografias e vídeos, que representou os dados para a elaboração do vídeo intitulado "Transgênicos em Libras”, disponibilizado na página do Facebook "Agrobiodiversidade" disponibilizado no formato de REA. (<https://www.youtube.com/watch?v=qpADrBVOYo4\&feature=share $>$ ) 


\section{CONSIDERAÇÕES FINAIS}

$\mathrm{Na}$ dimensão que constitui as práticas pedagógicas pode-se considerar que houve os resultados qualitativos reais emergidos de uma proposta considerada imaginária por profissionais em educação que ainda fiam-se somente nas práticas estáticas, como se vê em muitas práticas de ensino de uma língua estrangeira.

Também, pode-se afirmar que a pesquisa participante revela as possibilidades de solidificar ações pedagógicas intencionais e planejadas, voltadas para a formação multidirecional do aluno no ensino superior, destituindo a mística de se voltar para mercado de trabalho descartável. Permite a formação crítica, trabalho colaborativo, o uso de redes sociais para as pesquisas virtuais, experiência em trabalhar em grupos, a aplicabilidade real dos conceitos adquiridos, a flexibilidade do pensamento e tomada de decisões na elaboração de uma atividade coletiva, que compactuam com as habilidades solicitadas pela RRI e os objetivos do Projeto Engage.

Verifica-se que transpôs a proposta inicial de discutir um tema relevante para o futuro da humanidade, pois, os alunos elaboraram textos informativos e de opiniões em um vídeo que prestará como fonte de pesquisa e prosseguimento e gerador de outros temas de discussões que necessitam constituir pautas novos temas de discussões.

O ponto de destaque foi que todas as expressões comunicativas foram realizadas em Libras, na qual, a professora pode atuar como mediadora num contexto do Ensino Superior, que foi abalizado pelos 350 participantes, registrado e disponibilizado em vídeo no formato de REA.

Há de destacar o envolvimento dos alunos e os resultados apresentados, que uma proposta de estudo deve ser intencional nos objetivos educacionais e suscitar a inclusão em debate global para o futuro da humanidade.

Assim, os alunos demonstraram que não precisam ser meros expectadores de uma formação obsoleta e descartável, mas que são criativos, críticos e capazes de elaborarem os saberes e disponibilizarem como coautores das ações de inclusão e compartilhamento pela vida.

\section{REFERÊNCIAS}

André, M. E.D.A. (2009). O Papel da Pesquisa Na Formacao do Professor. In: Mizukami, Maria das Graças N.; Reali, Aline. (Org.). Formação de Professores - Tendências atuais. 9 ed. São Carlos, SP: EDUFSCAR, v. 1, p. 95-105.

Barreto, R. G. (2002). Formação de professores, tecnologias e linguagens. São Paulo: Edições Loyola.

Behrens, M. A. (2011). Paradigma da complexidade. Metodologia de projetos, contratos didáticos e portfólios. 3. ed. Petrópolis: Vozes. 
Brasil. (1996). Ministério da Educação e Cultura. Lei das Diretrizes e Bases da Educação Nacional n. 9.394 de 20 de dez. 1996. Disponível em: <http://www.presidencia.gov. br/ ccivil_03/Leis/L9394.htm>. Acesso em: 24 set. 2016.

Brasil. (2007). Declaração de Salamanca, 1994. Disponível em: <www.mec.gov.br /portal>. Acesso: 01 maio 2007.

Brasil. (2005). Decreto Federal n. 5626/2005. Regulamenta a Lei 10.436/2002 que oficializa a Língua Brasileira de sinais - Libras. Disponível em: <http://www.diadiaeducacao.pr.gov. br/portals/portal/institucional/dee/dee_surdez.php>. Acesso em: 15 out. 2016.

Brasil. (2011). Decreto n. 7.611, de 17 de novembro de 2011. Disponível em: <http:// www.planal-to.gov.br/ccivil_0_Ato2011-2014/2011/Decreto/D7611.htm>. Acesso em: 12 abr. 2016.

Comissão Europeia. (2012). Responsible research and innovation: Europe's ability to respond to societal challenges, Brussels, European Union. 2012. Disponível em: <http:// ec.europa.eu/research/sciencesociety/document_library/pdf_06/responsibleresearch-and-innovation-leaflet_en.pdf>. Acesso em: 10 set. 2015.

Creative Commons Brasil. (2013). Licenciamento aberto para a sociedade da informação. Disponível em: <http://creativecommons.org.br/>. Acesso em: 10 abr. 2013.

Denari, F. (2008). Dimensões teórico-práticas da educação inclusiva. In: Dechichi, C. \& Lázar, S. A. Inclusão escolar e educação especial: teoria e prática na diversidade, p. $37-$ 49. Uberlândia: Edufu.

Dorziat, A. (2008). Educação especial e inclusão escolar: prática e/ou teoria. In: Dechichi, C. \& Lázar, S. A. Inclusão escolar e educação especial: teoria e prática na diversidade, p. 21-36. Uberlândia: Edufu.

Greenwood, D. J., \& Levin, M. (2006). Reconstruindo as relações entre as universidades e a sociedade por meio da pesquisa-ação. In: N. K. Denzin, \& Y. S. Lincoln, O planejamento da pesquisa qualitativa: teorias e abordagens. 2. ed., cap. 3. Porto Alegre: Artmed.

Felipe, T. (2005). A. Libras em contexto: curso básico. (livro do estudante). 8. ed. Rio de Janeiro: WalPrint Gráfica e Editora.

Haguette, T. M. F. (2003). Metodologias qualitativas na Sociologia. 10. ed. Petrópolis: Vozes, 224p.

Lacerda. C. B. F. \& Santos, L. F. (Org.). (2014). Tenho um aluno surdo, e agora? introdução à libras e educação de surdos. São Carlos: EdUFSCar.

Okada, A. (2008). Aprendizagem aberta e estratégias de webconferência. Revista CoLearn Projeto OpenLearn the Open University UK. Nov. n. 1, v. 1, p. 1-6. Disponível em: $<$ http://labspace.open.ac.uk/journal>.

Okada, A., Young, G. \& Sherborne, T. (2015). Innovative teaching of responsible research and innovation in science education. E-Leaning Papers, Open Education Europa Journal, 2015. Disponível em: <http://engagingscience/en/documents>. Acesso em: 10 set. 2015. 
Pereira, T. I. \& Silva, L. F. S. (2010). As políticas públicas do ensino superior no governo Lula: expansão ou democratização? 10 Revista Debates, Porto Alegre, v. 4, n. 2, p. 10 31, jul.-dez. 2010. Disponível em: <http://flacso.redelivre.org.br/files/2013/03/1117.pdf>. Acesso em: 12 out. 2016.

REA. (2017). Recursos educacionais abertos. Disponível em: <http://rea.net.br/site/>. Acesso em: 10 abr.

Santana, B. (2012). Materiais didáticos digitais e recursos educacionais abertos. In: Santana, B.; Rossini, C. \& Pretto, N. de L. (Org.). Recursos educacionais abertos: práticas colaborativas políticas públicas. Salvador: Edufba; São Paulo: Casa da Cultura Digital, p. 17-33.

Shimazaki, N. M. (2017). O uso de REA para o ensino de libras nos cursos de graduação no ensino superior. Tese de doutorado em educação pelo programa de Pós-Graduação em educação da Pontifícia Universidade Católica do Paraná.

Slomski, V. G. (2012). Educação bilíngue para surdos: concepções e implicações práticas. 2. ed. Curitiba: Juruá.

Thiollent, Michel. (2007). Metodologia da pesquisa-ação. 9. ed. São Paulo: Cortez.

Torres, P. L. (2004). Laboratório on-line de aprendizagem: uma proposta crítica de aprendizagem colaborativa para a educação. Tubarão, SC: Unisul.

Torres, P. L. \& Irala, E. A. (2007). Aprendizagem colaborativa. In: Torres, P. L. (Org.). Algumas vias para entretecer o pensar e o agir. Curitiba, Senar.

Torres, P. L., Okada A. \& kowalski, R. P. G. (2016). Responsabilidade pesquisa e inovação: uma experiência de desenvolvimento de REA no formato de revistas, vídeos, aplicativos e games. Memorias de la Décima Quinta Conferencia Iberoamericana en Sistemas, Cibernética e Informática (CISCI 2016). Disponível em: <http://www.iiis.org/CDs2016/ CD2016Summer/papers/XA275YQ.pd>.

Torres, P. L., Fialho, N. N., Kowalski, R. P. G., Okada, A. (2016). Responsible research and innovation for the media facebook: community involvement in the study on agrobiodiversity. Creative Education, 7. Disponível em: <https://file.scirp. org/pdf/ CE_ 2016092014322017.pdf>. Acessado em: 25 nov. 2017.

Tsukamoto, N. M. S.; Fialho, N. N. (2014). O ensino de ciências para estudantes com surdez: a produção do conhecimento por meio de filmes. $2^{\circ}$ Congresso Internacional de Educação Científica, 15 Anos de Jornal da Educação Científica. Foz do Iguaçu, Paraná. United Nations Educational, Scientific and Cultural Organizacion (UNESCO). (2017). Recursos educacionais abertos. Disponível em: <http://www.unesco.org/new/en/communication-and-in-formation/access-to-knowledge/open-educational-resources/>. Acesso em: 26 abr. 2017. 